\title{
Kidney response to L-arginine treatment of carbon tetrachloride-induced hepatic injury in mice
}

\author{
Entsar A. Saad \\ Chemistry Department, Faculty of Science, Damietta University, New-Damietta, Egypt; entsarsaad@gmail.com
}

Received 5 November 2012; revised 10 December 2012; accepted 21 December 2012

\begin{abstract}
Hepatic injury can be induced by the administration of carbon tetrachloride $\left(\mathrm{CCl}_{4}\right)$ via the production of free radicals. The present work was initiated to investigate the kidney response to hepatic injury induced by $\mathrm{CCl}_{4}$ and its treatment by L-arginine. Female Swiss albino mice were supplied with L-arginine for 6 days (orally, $200 \mathrm{mg} / \mathrm{kg}$ body weight) prior or post to hepatic injury induction through i.p. injection with a single dose of $\mathrm{CCl}_{4}(20 \mathrm{mg} / \mathrm{kg}$ body weight) for $24 \mathrm{~h}$. After hepatic injury induction, renal MDA content was significantly elevated while renal GSH level and the activities of antioxidant enzymes (GR, GPx, GST, catalase, and SOD) were significantly decreased. These results suggest that $\mathrm{CCl}_{4}$ not only induces hepatic injury but also induces kidney dysfunction side by side. Following the treatment with L-arginine, all levels were almost back to normal. Therefore, Larginine administration is found to be an effective protector of both liver and kidney against $\mathrm{CCl}_{4}$-intoxication.
\end{abstract}

Keywords: L-Arginine; Hepatic Injury; Kidney; Lipid Peroxidation; Antioxidant Enzymes

\section{INTRODUCTION}

L-arginine plays important roles in the metabolism of an organism. It is the precursor for the synthesis of proteins and other molecules of great biological importance. For young organisms L-arginine is an essential amino acid for optimal growth and development. Therefore it must be provided in the diet. For adults, L-arginine is a semi-essential or conditionally essential amino acid, especially in such conditions as trauma, burn injury, smallbowel resection, and renal failure [1]. In adults, L-arginine is produced in the kidney from circulating citrulline synthesized by enterocytes in the small intestine [2]. Renal L-arginine synthesis is regulated by L-arginine plasma levels. L-arginine is synthesized in the proximal tubule of the kidney thus renal ischemia reperfusion injury as seen after shock, trauma and major vascular surgery, leading to acute tubular necrosis, might reduce Larginine production [3].

Several experimental studies have revealed that the administration of L-arginine can reduce renal ischemia reperfusion injury to skeletal muscle, kidney, liver, heart and brain. Moreover, L-arginine administration improves cardiovascular, pulmonary, immune, digestive functions, protects against the early stages of cancerogenesis and causes protective hemodynamic alterations. However, in situations with a stimulated inducible nitric oxide synthase (iNOS), the administration of large amounts of L-arginine is considered to be hazardous for the patients $[1,4]$. L-arginine is beneficial in the treatment of hepatic injury [5], hepatic cirrhosis, fatty liver degeneration [6-8] and diabetic nephropathy $[9,10]$. In several studies, administration of exogenous L-arginine has been shown to protect the kidney against toxic or ischemic injury. The molecular mechanisms for these beneficial effects are unclear [11].

Carbon tetrachloride $\left(\mathrm{CCl}_{4}\right)$ administration produces pathological changes not only in liver but also in different organs [12]. The exposure to $\mathrm{CCl}_{4}$ showed significant alterations in the lipolytic activities of liver, adipose tissue and kidney [13]. $\mathrm{CCl}_{4}$ induces oxidative stress via the production of free peroxy radicals and lipoperoxides thereby damaging proteins, DNA and lipids [14]. The involvement of free radical-mediated oxidative process in the development of $\mathrm{CCl}_{4}$ hepatotoxicity is well established [15]. It was reported that impairment of hepatic antioxidant status is associated with a substantial heaptocellular damage induced by $\mathrm{CCl}_{4}$ [16]. GSH is a crucial determinant of tissue susceptibility to oxidative damage, and the depletion of hepatic GSH content was shown to be associated with the enhanced toxicity of chemicals including $\mathrm{CCl}_{4}$ [17].

Liver is the main target for $\mathrm{CCl}_{4}$ toxicity while the kidney is the main site of $\mathrm{CCl}_{4}$ accumulation. The pathogenesis of $\mathrm{CCl}_{4}$-induced renal dysfunction is not completely understood [18]. Whether the induction of renal 
dysfunction caused by $\mathrm{CCl}_{4}$ is dependent on the functional status of the liver or not is still under investigation. Larginine was found to be effective in the treatment of $\mathrm{CCl}_{4}$-induced hepatic injury [5]. Accordingly, the present study was conducted to: 1) investigate whether a single dose of $\mathrm{CCl}_{4}$ (20 mg/kg body weight) can induce renal dysfunction along with hepatic injury and 2) to examine the ability of L-arginine to treat such conditions via monitoring the kidney lipid peroxide level and activities of antioxidant enzymes (SOD, catalase, GR, GPx and GST).

\section{MATERIALS AND METHODS}

\subsection{Chemicals}

$\mathrm{CCl}_{4}$ and L-arginine were obtained from Sigma Chemical Co. (St. Louis, MO, USA). All other chemicals used throughout this investigation were of the highest analytical grade commercially available.

\subsection{Animals}

Forty female Swiss albino mice (25 \pm 2 gm) obtained from Theodor Bilharz Research Institute, Cairo (Egypt) were used in this experiment. The experiment was performed according to the approved ethical rules. The animals were housed for about one month prior to experimental use. All mice were housed under constant conditions of a 12-hour light/dark cycle in a temperature and humidity controlled room, and were maintained according to the criteria outlined in the "Guide for the Care and Use of Laboratory Animals” prepared by the National Academy of Sciences and published by the National Institutes of Health [19]. Food and water ad libitum were allowed.

\subsection{Treatment}

The animals were randomly divided into 4 groups of 10 mice each. $\mathrm{CCl}_{4}$ group; received a 6-day repeated oral dose of Tween $80(1 \mathrm{ml} / \mathrm{kg})$ diluted in distilled water $(1 \%$, $\mathrm{v} / \mathrm{v})$ then mice were injected with a single dose of $\mathrm{CCl}_{4}$ (20 mg/kg body weight, intraperitoneally (i.p.)) dissolved in corn oil (2\%, v/v) as described previously [20,21] and sacrificed after $24 \mathrm{~h}$ of $\mathrm{CCl}_{4}$ injection. For protection group, mice were orally supplemented with a dose of Larginine (200 mg) in $1 \mathrm{ml}$ Tween/kg body weight/day for 6 days, then injected i.p. with a single dose of $\mathrm{CCl}_{4}(20$ $\mathrm{mg} / \mathrm{kg}$ body weight) and sacrificed $24 \mathrm{~h}$ later. For curative group; mice were injected i.p. with a single dose of $\mathrm{CCl}_{4}$ (20 mg/kg body weight), then after $24 \mathrm{~h}$ mice were orally treated with $200 \mathrm{mg}$ L-arginine in $1 \mathrm{ml}$ Tween/kg body weight/day for 6 days, then sacrificed. Finally, normal control group was fed with the control diet and received the respective vehicles only (received a 6-day repeated oral dose of $1 \%$ Tween $80(1 \mathrm{ml} / \mathrm{kg})$ then a sin- gle i.p. dose of corn oil was injected then mice were sacrificed $24 \mathrm{~h}$ later).

\subsection{Samples}

The animals of each group were sacrificed by decapitation at the end of the 8th day of the experiment. Blood samples were collected and serum was separated by centrifugation at $5000 \mathrm{rpm}$, for $10 \mathrm{~min}$ and stored at $4^{\circ} \mathrm{C}$. The kidneys were removed by dissection, rapidly rinsed with ice-cold saline and dried on filter paper, homogenized in $0.9 \% \mathrm{NaCl}$ solution using a homogenizer and the resultant homogenate $(10 \%, \mathrm{w} / \mathrm{v})$ was then centrifuged at $5000 \mathrm{rpm}$ for $15 \mathrm{~min}$ at $4^{\circ} \mathrm{C}$ and the resultant supernatant was used for the determination of biochemical parameters.

\subsection{Biochemical Measurements}

Serum creatinine was measured to assess kidney function using Jaffe alkaline picrate method (Randox, UK) [22]. GSH content was estimated spectrophotometrically at $412 \mathrm{~nm}$, using Ellman's reagent as described previously [23]. The enzyme GPx (EC 1.11.1.9) activity was determined by its ability to catalyze the oxidation of GSH by t-butylhydroperoxide, in the presence of glutathione reductase and NADPH. The oxidized glutathione was then immediately converted to the reduced form with a concomitant oxidation of NADPH to NADP+ and the decrease in absorbance was measured at $340 \mathrm{~nm}$ [24]. GR (EC 1.8.1.7) activity was estimated by following the decrease in absorbance at $340 \mathrm{~nm}$ due to the oxidation of NADPH to NADP+ accompanied with the reduction of GSSG [25]. The activity of GST (EC 2.5.1.18) was determined by measurement of the rate of GSH conjugation with 1-chloro-2,4-dinitrobenzene as substrate [26]. Activity of SOD (EC 1.15.1.1) enzyme was estimated by the degree of inhibition of the reduction of nitroblue tetrazolium dye mediated by phenazine methosulfate [27]. Catalase (EC 1.11.1.6) activity was kinetically measured by monitoring the rate of decomposition of hydrogen peroxide as substrate [28]. The level of MDA, as an end product of lipid peroxidation, was determined by its ability to react with thiobarbituric acid forming a 1:2 adduct [29]. Protein concentration was determined using the Bradford method with bovine serum albumin as the standard [30].

\subsection{Statistical Analysis}

The results are expressed as mean \pm SD. Statistical analysis between two groups was performed using Student's t-test; $P<0.05$ was considered statistically significant. The data were analyzed with GraphPad InStat version 2.03 (GraphPad Software, Inc., CA, USA). 


\section{RESULTS}

\subsection{Effects on Serum Creatinine Level}

$\mathrm{CCl}_{4}$ injection resulted in a significant increase in serum creatinine level compared with those of the control group. On the other hand, pre- or post-administration of L-arginine resulted in a significant decrease in the serum creatinine level (Table 1).

\subsection{Effects on Renal Lipid Peroxidation and GSH Level}

MDA level, as a marker of free radical mediated lipid peroxidation injury, was significantly elevated in the kidney homogenate of $\mathrm{CCl}_{4}$-intoxicated mice compared with that of the normal group and it was significantly decreased by pre- or post-treatment with L-arginine to back again around the normal range. On contrary, renal GSH level was significantly decreased in $\mathrm{CCl}_{4}$-intoxicated mice as compared with the normal group and it was significantly increased by both pre and post-administration of L-arginine (Table 2).

\subsection{Effects on Antioxidant Enzymes}

GR, GPx, GST, catalase and SOD (antioxidant enzymes) were evaluated as an index of antioxidant status of tissues. As shown in Figures 1-3, renal activities of GR, GPx, GST, catalase and SOD enzymes were significantly inhibited by $\mathrm{CCl}_{4}$ intoxication compared with those of normal mice group. The activities of the antioxidant enzymes were significantly enhanced by pre-treatment or post-treatment of $\mathrm{CCl}_{4}$-intoxicated mice with L-arginine compared with those of untreated $\mathrm{CCl}_{4}$-intoxicated mice group.

\section{DISCUSSION}

Previous studies reported that $\mathrm{CCl}_{4}$ induces hepatic injury by producing free radicals [31-33]. Here and in accordance with others [5], single i.p. dose of $\mathrm{CCl}_{4}(20$ $\mathrm{mg} / \mathrm{kg}$ body weight) causes hepatic injury in mice and the administration of L-arginine improved the resistance of hepatic cells to the damaging action of $\mathrm{CCl}_{4}$, indicating the hepatoprotective and hepatocurative activity of

Table 1. Effects of $\mathrm{CCl}_{4}$ intoxication and pre- or post-treatment with L-arginine on serum creatinine level of mice with $\mathrm{CCl}_{4}{ }^{-}$ induced hepatic injury.

\begin{tabular}{cc}
\hline Animal groups & Serum creatinine $(\mathrm{mg} \%)$ \\
\hline Normal $\mathrm{CCl}_{4}$ & $0.46 \pm 0.02$ \\
Protection & $0.64 \pm 0.03^{*}$ \\
Curative & $0.48 \pm 0.02^{!}$ \\
\hline
\end{tabular}

Each value represents the mean \pm SD of ten mice. ${ }^{*}$ Significant difference at $P<0.001$ level compared with the normal group. 'Significant difference at $P<$ 0.001 level compared with the $\mathrm{CCl}_{4}$ group.
L-arginine against the acute intoxication of $\mathrm{CCl}_{4}$ (data not shown).

Acute and chronic renal damage are also very common pathophysiologic disturbances caused by $\mathrm{CCl}_{4}[31$, 34]. Repeated administration of $\mathrm{CCl}_{4}$ to the experimental animals not only produces liver cirrhosis but also pathological changes in different organs such as lung, spleen and kidneys [12]. In the current supplementary study, and in accordance with others [35], elevated level of serum creatinine was taken as a presumptive marker of lesions in kidneys. Bhadauria et al. [36], reported that administration of $\mathrm{CCl}_{4}$ altered various diagnostically important biochemical variables in rats and multiple treatment of propolis significantly inhibited lipid peroxidation and markedly enhanced glutathione in liver and kidney. Dogukan et al. [18] showed that oxidative stress plays a role in $\mathrm{CCl}_{4}$-induced renal injury. Ogeturk et al. [37] found that kidney MDA levels were increased significantly following $\mathrm{CCl}_{4}$ exposure. In the study of Tirkey et al. [31], thiobarbituric acid reactive substances (TBARS) levels were significantly increased whereas GSH, SOD and catalase levels were decreased in the liver and kidney homogenates of $\mathrm{CCl}_{4}$-intoxicated rats. The present study showed a significant increase $(P<0.001)$ of MDA in the mice kidney homogenate whereas a significant decrease $(P<0.001)$ of the renal GSH was observed compared to those of the normal control after injection of a single dose of $\mathrm{CCl}_{4}$ that induced the acute hepatic injury. Moreover, the results showed that $\mathrm{CCl}_{4}$ intoxication significantly decreased renal activities of antioxidant enzymes (SOD, catalase, GPx, GST and GR) as compared to normal mice. These results were in accordance with those of Shi et al. [38]. These data revealed that, increased level of free radicals is associated with decreased antioxidant status in liver and kidney of animals treated with $\mathrm{CCl}_{4}$. This finding is similar to others [39,40]. Moreover, these results demonstrate that the single $\mathrm{CCl}_{4}$ dose $(20 \mathrm{mg} / \mathrm{kg}$ body weight) is able to induce both hepatic injury and kidney dysfunction suggesting that the effect of $\mathrm{CCl}_{4}$ on kidney function depends on the functional status of the liver which is in accordance with other observations reported previously [41].

Furthermore, the alteration in the antioxidant enzyme activities may be relevant to the ability of the liver and kidney to cope with oxidative stress after $\mathrm{CCl}_{4}$ poisoning.

The pre- or post-treatment with L-arginine significantly decreased serum creatinine to be around normal levels as well as kidney MDA. On the other hand, the kidney levels of GSH and antioxidant enzyme activities (SOD, catalase, GPx, GST and GR) significantly increased as compared to $\mathrm{CCl}_{4}$-intoxicated mice. It was hypothesized that dietary L-arginine supplementation attenuates oxidative damage in kidneys [10]. In 2002, Mansour et al. [42] 
Table 2. Effects of $\mathrm{CCl}_{4}$ intoxication and pre- or post-treatment with L-arginine on renal MDA and renal $\mathrm{GSH}$ levels of mice with $\mathrm{CCl}_{4}$-induced hepatic injury.

\begin{tabular}{ccccc}
\hline Animal groups & Normal & $\mathrm{CCl}_{4}$ & Protection & Curative \\
\hline MDA $(\mu \mathrm{M} / \mathrm{mg}$ protein $)$ & $4.96 \pm 0.28$ & $6.42 \pm 0.52^{*}$ & $4.35 \pm 0.63^{!}$ & $4.49 \pm 0.10^{!}$ \\
GSH $(\mu \mathrm{M} / \mathrm{mg}$ protein $)$ & $7.69 \pm 0.37$ & $3.92 \pm 0.86^{*}$ & $6.61 \pm 0.73 !$ & $7.14 \pm 0.75^{!}$ \\
\hline
\end{tabular}

Each value represents the mean \pm SD of ten mice. "Significant difference at $P<0.001$ level compared with the normal group. 'Significant difference at $P<0.001$ level compared with the $\mathrm{CCl}_{4}$ group.

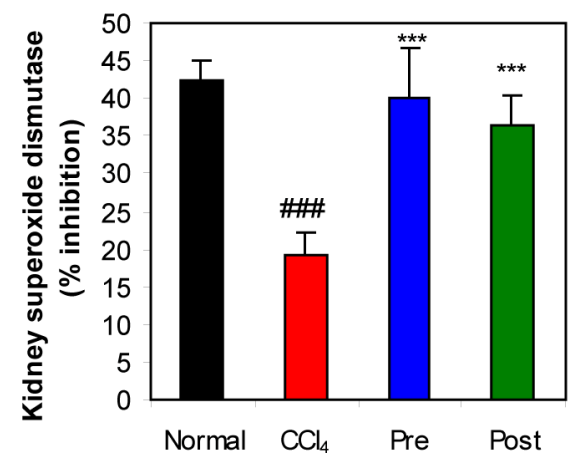

(a)

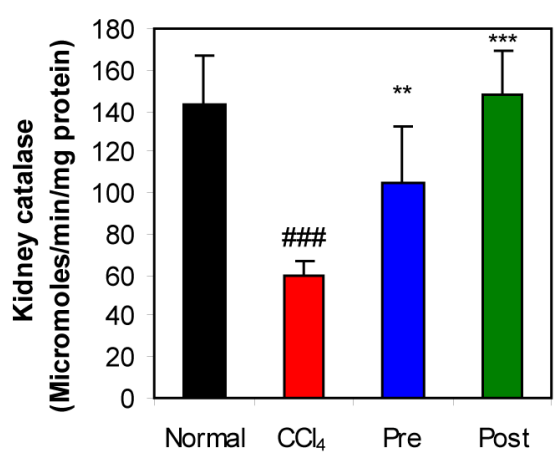

(b)

Figure 1. Effects of pre- or post-treatment with L-arginine on the renal superoxide dismutase activity (a) and the renal catalase activity (b) in $\mathrm{CCl}_{4}$-induced hepatic injury in mice. Each bar represents the mean \pm SD of ten mice. ${ }^{\# \# \#}$ Significant difference at $P<0.001$ level compared with the normal group. ${ }^{* *}$, ${ }^{* * *}$ Significant difference at $P<0.01$ and at $P<0.001$ levels compared with the $\mathrm{CCl}_{4}$ group, respectively.

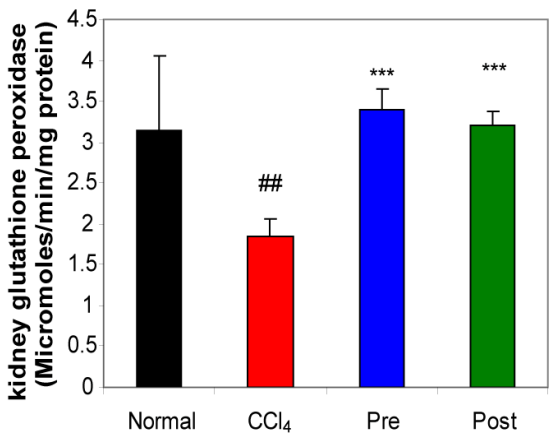

(a)

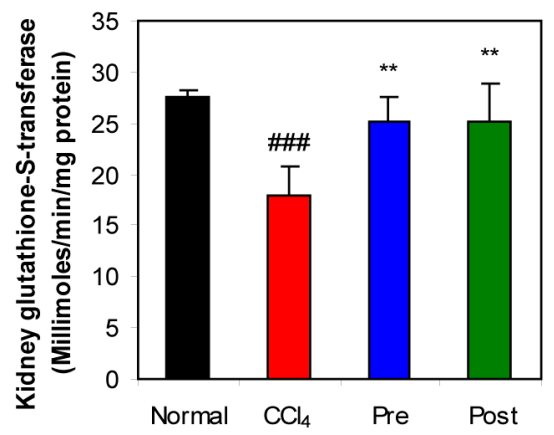

(b)

Figure 2. Effects of pre- or post-treatment with L-arginine on the renal glutathione peroxidase activity (a) and the renal glutathione-S-transferase activity (b) in $\mathrm{CCl}_{4}$-induced hepatic injury in mice. Each bar represents the mean \pm SD of ten mice. ${ }^{\# \#, ~ " \# \# ! ~ S i g n i f i c a n t ~ d i f f e r e n c e ~ a t ~} P<0.01$ and at $P<0.001$ levels compared with the normal group, respectively. ${ }^{* *},{ }^{* * * *}$ Significant difference at $P<0.01$ and at $P<0.001$ levels compared with the $\mathrm{CCl}_{4}$ group, respectively.

observed that oral administration of L-arginine before cyclosporine (CsA) injection produced a significant protection against nephrotoxity induced by CsA, prevented the rise of MDA as well as reduction of GPx activity and reduced GSH content in kidney tissue. These suggested that, L-arginine can ameliorate kidney dysfunction. In another study of Saleh and El-Demerdash [43], they reported that cisplatin induced an increase in the level of lipid peroxides and oxidized glutathione and a depletion of GSH. The activities of the antioxidant enzymes GPx and SOD were also lowered. L-arginine significantly attenuated the oxidative stress and nephrotoxic effect of cisplatin.

The present study revealed that L-arginine treatment significantly decreased renal MDA level while enhanced renal GSH levels and increased the activities of antioxidant enzymes (SOD, catalase, GPx, GST and GR). The toxicity of $\mathrm{CCl}_{4}$ can be explained on the basis of oxidative stress. These results indicated that besides the heaptoprotective and hepatocurative action of L-arginine [5], it can ameliorate the kidney dysfunction and that was related to the improvement of the functional status of the liver.

Finally, it can be concluded that a single $\mathrm{CCl}_{4}$ dose (20 


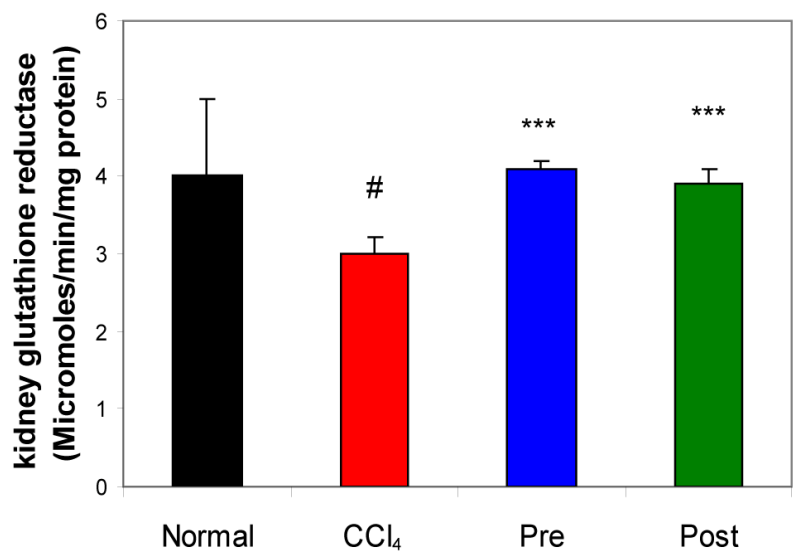

Figure 3. Effects of pre- or post-treatment with L-arginine on the renal glutathione reductase activity in CCl4-induced hepatic injury in mice. Each bar represents the mean \pm SD of ten mice. "Significant difference at $P<0.05$ level compared with the normal group. ${ }^{* * *}$ Significant difference at $P<0.001$ level compared with the $\mathrm{CCl}_{4}$ group.

$\mathrm{mg} / \mathrm{kg}$ body weight) is able to induce hepatic injury and kidney dysfunction. In addition, the effect of $\mathrm{CCl}_{4}$ on kidney function depends on the functional status of the liver. L-arginine has protective effects on both liver and kidney against $\mathrm{CCl}_{4}$ toxicity and these protective effects can be interpreted via the inhibition of $\mathrm{CCl}_{4}$ derived free radicals production and the enhancement of antioxidant enzymes activities as well as through the antioxidant effects of L-arginine itself. Thus, clinical application of Larginine should be considered in cases with hepatic and renal $\mathrm{CCl}_{4}$-induced injury.

\section{REFERENCES}

[1] Scibior, D. and Czeczot, H. (2004) Arginine-metabolism and functions in the human organism. Postepy Higieny $i$ Medycyny Doświadczalnej, 58, 321-332.

[2] Wouter, J., Karin, L., Anje, A., Sander, J.H., Martijn, A., Reina, E., Jan, M., Marinus, C. and Wouter, H. (2002) Arginine deficiency affects early B cell maturation and lymphoid organ development in transgenic mice. Journal of Clinical Investigation, 110, 1539-1548.

[3] Prins, H.A., Nijveldt, R.J., Gasselt, D.V., van Kemenade, F., Teerlink, T., van Lambalgen, A.A., Rauwerda, J.A. and van Leeuwen, P.A. (2002) The flux of arginine after ischemia-reperfusion in the rat kidney. Kidney International, 62, 86-93. doi:10.1046/j.1523-1755.2002.00409.x

[4] Roth, E. (1998) The impact of L-arginine-nitric oxide metabolism on ischemia/reperfusion injury. Current Opinion in Clinical Nutrition \& Metabolic Care, 1, 97-99. doi:10.1097/00075197-199801000-00016

[5] Saad, E.A. (2012) Curative and protective effects of Larginine on carbon tetrachloride-induced hepatotoxicity in mice. Biochemical and Biophysical Research Communications, 423, 147-151. doi:10.1016/j.bbrc.2012.05.102

[6] Balch, M.D., James, F., Balch, C.N.C. and Phyllis, A.
(1997) Prescription for nutritional healing. 2nd Edition, Avery Publishing Group, Garden City Park, 35-36.

[7] Bravermanm, E.R. (1997) The healing nutrients. Keats Publishing, Inc., New Canaan, 18-23.

[8] Hendler, M.D. and Saul, S. (1990) The doctor's vitamin and mineral encyclopedia. Fireside, New York, 209-215.

[9] Huang, K.H., Pai, M.H., Wu, C.H., Liu, J.J. and Yeh, S.L. (2010) Supplemental dietary arginine reduces renal RAGE expression and oxidative damage in rats with streptozotocin-induced type 2 diabetes. European e-Journal of Clinical Nutrition and Metabolism, 5, e77-e84.

[10] Hu, Y.-M., Yeh, C.-L. Pai, M.-H., Li, C.-C., Liu, J.-J. and Yeh, S.-L. (2012) Effects of arginine supplementation on exogenous advanced glycation end product-induced renal inflammatory mediator expression in rats. Journal of Experimental \& Clinical Medicine, 4, 24-29. doi:10.1016/j.jecm.2011.11.004

[11] Cherla, G. and Jaimes, E.A. (2004) Role of L-arginine in the pathogenesis and treatment of renal disease. Journal of Nutrition, 134, 2801S-2806S.

[12] Dashti, H., Behbehani, A., Abul, H., Hussain, T. and Madda, P. (1995) Alterations of trace elements in kidney, spleen and lungs in treated and untreated experimental liver cirrhosis. Journal of the Royal College of Surgeons of Edinburgh, 40, 173-179.

[13] Patil, S., Kanase, A. and Varute, A.T. (1989) Effect of hepatoprotective ayurvedic drugs on lipases following $\mathrm{CCl}_{4}$ induced hepatic injury in rats. Indian Journal of Experimental Biology, 27, 955-958.

[14] Khan, M.R. and Younus, T. (2011) Prevention of $\mathrm{CCl}_{4}{ }^{-}$ induced oxidative damage in adrenal gland by Digera muricata extract in rat. Journal of Pharmaceutical Sciences, 24, 469-473.

[15] Camandola, S., Aragno, M., Cutrin, J.C., Tamagno, E., Danni, O., Chiarpotto, E., Parola, M., Leonarduzzi, G., Biasi, F. and Poli, G. (1999) Liver AP-1 activation due to carbon tetrachloride is potentiated by 1,2-dibromoethane but is inhibited by alpha-tocopherol or gadolinium chloride. Free Radical Biology and Medicine, 26, 1108-1116. doi:10.1016/S0891-5849(98)00298-6

[16] Dwivedi, S., Sharma, R., Sharma, A., Zimniak, P., Ceci, J.D., Awasthi, Y.C. and Boor, P.J. (2006) The course of CCl4 induced hepatotoxicity is altered in mGSTA4-4 null (-/-) mice. Toxicology, 218, 58-66. doi:10.1016/j.tox.2005.10.012

[17] Navarro, J., Obrador, E., Carretero, J., Petschen, I., Avino, J., Perez, P. and Estrela, J.M. (1999) Changes in glutathione status and the antioxidant system in blood and in cancer cells associate with tumour growth in vivo. Free Radical Biology and Medicine, 26, 410-418. doi:10.1016/S0891-5849(98)00213-5

[18] Dogukan, A., Akpolat, N., Celiker, H., Ilhan, N., Bahçecioglu, I.H. and Günal, A.I. (2003) Protective effect of interferon- $\alpha$ on carbon tetrachloride-induced nephrotoxicity. Journal of Nephrology, 16, 81-84.

[19] National Institutes of Health (1996) Guide for the care and use of laboratory animals. 7th Edition, National Academy Press, Washington DC. 
[20] Lee, K.J. and Jeong, H.G. (2002) Protective effect of Platycodi radix on carbon tetrachloride-induced hepatotoxicity. Food and Chemical Toxicology, 40, 517-525. doi:10.1016/S0278-6915(01)00104-1

[21] Lee, K.J., Woo, E.R., Choi, C.Y., Shin, D.W., Lee, D.G., You, H.J. and Jeong, H.G. (2004) Protective effect of acteoside on carbon tetrachloride-induced hepatotoxicity. Life Sciences, 74, 1051-1064. doi:10.1016/j.lfs.2003.07.020

[22] Bartels, H. and Boehmer, M. (1971) Microdetermination of creatinine. Clinica Chimica Acta, 32, 81.

[23] Beutler, E., Duron, O. and Kelly, B.M. (1963) Improved method for the determination of blood glutathione. Journal of Laboratory and Clinical Medicine, 61, 882-888.

[24] Beutler, E. (1975) Glutathione peroxidase. In: Beutler, E., Ed., Red Cell Metabolism: A Manual of Biochemical Methods, Grune \& Stratton, New York, 71-73.

[25] Beutler, E. (1969) Effect of flavin compounds on glutathione reductase activity: in vivo and in vitro studies. Journal of Clinical Investigation, 48, 1957-1966. doi:10.1172/JCI106162

[26] Habig, W.H., Pablst, M.J. and Jakoby, W.B. (1974) Glutathione-S-transferases. The first enzymatic step in mercapturic acid formation. Journal of Biological Chemistry, 249, 7130-7139.

[27] Dechaatelet, L.R., McCall, C.E., McPhail, L.C. and Johnston Jr., R.B. (1974) Superoxide dismutase activity in leukocytes. Journal of Clinical Investigation, 53, 11971201. doi:10.1172/JCI107659

[28] Chance, B. and Mackley, A. (1955) Assays of catalases and peroxides. Methods in Enzymology, 2, 764-775. doi:10.1016/S0076-6879(55)02300-8

[29] Ohkawa, H., Ohishi, N. and Yagi, K. (1979) Assay for lipid peroxides in animal tissues by thiobarbituric acid reaction. Analytical Biochemistry, 95, 351-358. doi:10.1016/0003-2697(79)90738-3

[30] Bradford, M.M. (1976) A rapid and sensitive method for the quantitation of microgram quantities of protein utilizing the principle of protein-dye binding. Analytical Biochemistry, 72, 248-254. doi:10.1016/0003-2697(76)90527-3

[31] Tirkey, N., Pilkhwal, S., Kuhad, A. and Chopra, K. (2005) Hesperidin, a citrus bioflavonoid, decreases the oxidative stress produced by carbon tetrachloride in rat liver and kidney. BMC Pharmacology, 5, 2-10. doi:10.1186/1471-2210-5-2

[32] Weber, L.W.D., Bull, M. and Stampfl, A. (2003) Hepatotoxicity and mechanism of action of haloalkanes: Carbon tetrachloride as a toxicological model. Critical Reviews in Toxicology, 33, 105-136. doi:10.1080/713611034

[33] Yang, Y.S., Ahn, T.H., Lee, J.C., Moon, C.J., Kim, S.H., Jun, W., Park, S.C., Kim, H.C. and Kim, J.C. (2008) Pro- tective effects of Pycnogenol on carbon tetrachloride-induced hepatotoxicity in Sprague-Dawley rats. Food and Chemical Toxicology, 46, 380-387. doi:10.1016/j.fct.2007.08.016

[34] Manna, P., Sinha, M. and Sil, P.C. (2006) Aqueous extract of Terminalia arjuna prevents carbon tetrachloride induced hepatic and renal disorders. BMC Complementary and Alternative Medicine, 6, 33-43. doi:10.1186/1472-6882-6-33

[35] Sadiq, S., Nagi, A.H., Shahzad, M. and Zia, A. (2010) The reno-protective effect of aqueous extract of Carum carvi (black zeera) seeds in streptozotocin induced diabetic nephropathy in rodents. Saudi Journal of Kidney Diseases and Transplantation, 21, 1058-1065.

[36] Bhadauria, M., Nirala, S.K. and Shukla, S. (2008) Multiple treatment of propolis extract ameliorates carbon tetrachloride induced liver injury in rats. Food and Chemical Toxicology, 46, 2703-2712. doi:10.1016/j.fct.2008.04.025

[37] Ogeturk, M., Kus, I., Colakoglu, N., Zararsiz, I., Ilhan, N. and Sarsilmaz, M. (2005) Caffeic acid phenethyl ester protects kidneys against carbon tetrachloride toxicity in rats. Journal of Ethnopharmacology, 97, 273-280. doi:10.1016/j.jep.2004.11.019

[38] Shi, Z.M., Feng, P., Jiang, D.Q. and Wang, X.J. (2006) Mistletoe alkali inhibits peroxidation in rat liver and kidney. World Journal of Gastroenterology, 12, 4052-4055.

[39] Meki, A.R. and Hussein, A.A. (2001) Melatonin reduces oxidative stress induced by ochratoxin A in rat liver and kidney. Comparative Biochemistry and Physiology Part C: Toxicology \& Pharmacology, 130, 305-313. doi:10.1016/S1532-0456(01)00248-4

[40] Jurczuk, M., Brzoska, M.M., Moniuszko-Jakoniuk, J., Galazyn-Sidorczuk, M. and Kulikowska-Karpinska, E. (2004) Antioxidant enzymes activity and lipid peroxidation in liver and kidney of rats exposed to cadmium and ethanol. Food and Chemical Toxicology, 42, 429-438. doi:10.1016/j.fct.2003.10.005

[41] Rincon, A.R., Covarrubias, A., Pedraza-Chaverri, J., Poo, J.L., Armendariz-Borunda, J. and Panduro, A. (1999) Differential effect of $\mathrm{CCl}_{4}$ on renal function in cirrhotic and non-cirrhotic rats. Experimental and Toxicologic Pathology, 51, 199-205. doi:10.1016/S0940-2993(99)80094-3

[42] Mansour, M., Daba, M.H., Gado, A., Al-Rjkabi, A. and Al-Majed, A. (2002) Protective effect of L-arginine against nephrotoxicity induced by cyclosporine in normal rats. Pharmacological Research, 45, 441-446. doi:10.1006/phrs.2002.0968

[43] Saleh, S. and El-Demerdash, E. (2005) Protective effects of L-arginine against cisplatin-induced renal oxidative stress and toxicity: Role of nitric oxide. Basic \& Clinical Pharmacology \& Toxicology, 97, 91-97. doi:10.1111/j.1742-7843.2005.pto_114.x 